\title{
Azithromycin resistant gonococci: a literature review
}

\author{
Awoke Derbie $^{1,2,3^{*}}$ (D), Daniel Mekonnen ${ }^{1,3}$, Yimtubezinash Woldeamanuel ${ }^{2,4}$ and Tamrat Abebe ${ }^{4}$
}

\begin{abstract}
Objective: Gonorrhea is the second most common sexually transmitted bacterial infection (STI) next to Chlamydia. Untreated cases could results in major complications like pelvic inflammatory disease (PID), ectopic pregnancy, infertility, miscarriage, fetal death and congenital infections. Gonorrhea has been treated with antibiotics for more than eight decades. However, the emergence and spread of antimicrobial resistance (AMR) in gonococcus seriously compromises the management of the disease. The aim of this review was to describe the current developments in the field of azithromycin resistant gonococci.
\end{abstract}

Methods: Literatures published in English in the last 10 years were retrieved from PubMed, SCOPUS, Google scholar, Cochrane library and the Google databases using relevant searching terms.

Results: Gonococcus is capable of using a number of strategies to confer resistance as the bacterium has an extraordinary capacity to alter its genome. So far the accumulated data on the field showed that the world is heading towards a pandemic of extensively drug-resistant (XDR) gonococcus which is now seems to be evolving into a true "superbug". Hence, in the near future gonorrhea may become untreatable on the international basis unless new drugs become available.

An antibiotic resistance in gonococcus has been noted beginning in 1940s against sulfonamides. Since then, resistance has rapidly emerged to penicillins, tetracyclines, macrolides, fluoroquinolones, and cephalosporins. Currently, in most nations, the injectable extended-spectrum cephalosporin (ESC), i.e. ceftriaxone based therapy is the only remaining option for gonorrhea. Based on the WHO and the US-CDC recommendations, countries are increasingly using a combination of cephalosporin and azithromycin for the treatment of gonorrhoea. Azithromycin revolutionized gonoccocal therapy as it shortened treatment time by more than half from 7 to 14 days and improved patient compliance due to high tissue levels and long half-life. However, constantly emerging reports from different parts of the globe showed that $\mathrm{N}$. gonorrhoeae is developing significant level of resistance against azithromycin, and so far more than 33\% level of resistance was reported. Two strategies have been commonly implicated in gonococcal resistance against azithromycin: over expression of an efflux pump (due to mutations at $m$ trR coding region) and decreased antimicrobial affinity (due to mutations in genes encoding the 235 ribosomal subunit).

\footnotetext{
* Correspondence: awoke.derbie@bdu.edu.et; awe.love2000@gmail.com

'Department of Medical Microbiology, College of Medicine and Health Sciences, Bahir Dar University, Bahir Dar, Ethiopia

${ }^{2}$ Centre for Innovative Drug Development and Therapeutic Trials for Africa

(CDT-Africa), Addis Ababa University, Bahir Dar, Ethiopia

Full list of author information is available at the end of the article
}

(c) The Author(s). 2020 Open Access This article is licensed under a Creative Commons Attribution 4.0 International License, which permits use, sharing, adaptation, distribution and reproduction in any medium or format, as long as you give appropriate credit to the original author(s) and the source, provide a link to the Creative Commons licence, and indicate if changes were made. The images or other third party material in this article are included in the article's Creative Commons licence, unless indicated otherwise in a credit line to the material. If material is not included in the article's Creative Commons licence and your intended use is not permitted by statutory regulation or exceeds the permitted use, you will need to obtain permission directly from the copyright holder. To view a copy of this licence, visit http://creativecommons.org/licenses/by/4.0/ The Creative Commons Public Domain Dedication waiver (http://creativecommons.org/publicdomain/zero/1.0/) applies to the data made available in this article, unless otherwise stated in a credit line to the data. 
(Continued from previous page)

Conclusions: With no alternative antimicrobial treatment options for gonorrhoea and only a few new drugs in the development pipeline, it is necessary to monitor drug resistance and optimize treatment regimens regularly. Moreover, investigations for novel drugs should be wired.

Keywords: Neisseria gonorrhoeae, Gonococcus, Azithromycin, Resistance

\section{Introduction}

Annually an estimated 78 million new cases of gonorrhea occurred among people aged 15-49 years around the world. About $75-85 \%$ of the cases were in developing countries [1]. A sharp decline of gonorrhea incidence has been noted in many developed countries, but the disease remains one of the most common STIs in the developing world [1, 2]. Neisseria gonorrhoeae (Gonococcus), which is the etiological agent of gonorrhea, typically colonizes and infects the genital tract in men and women, but may be found in additional body sites such as the rectal and oropharyngeal mucosa with or without clinically evident infection [3-5]. It is transmitted through sexual contact and can also be passed from mother to child through infected birth canal [6-9].

Gonorrhea can be prevented by exercising safe sexual practice like, using condom and the disease is treatable and medications have been used for more than eight decades [10]. However, treatment has been greatly compromised by the emergence of drug resistance by $N$. gonorrhoeae for every drug used to treat it $[1,10]$. Because of its high affinity for horizontal gene transfer, antibiotic resistant gonorrhea is seen as an emerging public health threat around the globe $[3,11]$. The irrational and unwise use of antibacterial agents increases the development of antibiotic resistance in gonorrhoea as well as other bacterial diseases [5], especially in the developing countries $[1,7,12]$.

Since the introduction of antimicrobial treatment, resistance has rapidly emerged to sulphonamides, penicillins, tetracyclines, macrolides (like, azithromycin), fluoroquinolones, and early-generation cephalosporins. Currently, in most nations, the injectable extendedspectrum cephalosporin (ESC) ceftriaxone based therapy is the only remaining empiric treatment for gonorrhea. However, gonococcal in-vitro resistance and/or treatment failures to the last-line oral ESC cefixime and, more rarely, to ceftriaxone have been verified in many countries. Consequently, dual antimicrobial therapy, mainly ceftriaxone plus azithromycin is under practice in most countries $[8,10,13-15]$. Resistance of $N$. gonorrhoeae to azithromycin slowly developed since 1990 in some areas of the world and then a number of similar reports came to the front globally [14, 16-21].
Azithromycin was developed as a synthetic derivative of erythromycin in 1980s. It binds to the $50 \mathrm{~S}$ ribosome subunit preventing translocation of the peptidyl-tRNA, causing ribosomes to release incomplete polypeptides. This results in a bacteriostatic effect [22]. It had a significantly higher activity than erythromycin against $N$. gonorrhoeae [23]. However, studies in different parts of the globe showed that the world community is facing challenge due to significant level of drug resistance to azithromycin by some strains of gonococci [14, 23-28] and reports are showing that azithromycin resistance tended to increase $[29,30]$.

Standardized monitoring of the antimicrobial susceptibility profile has been restricted to some nations in the developed world; such as the Gonococcal Isolate Surveillance Project (GISP) in the US and Gonococcal Resistance to Antimicrobials Surveillance Program (GRASP) in England and Wales [7] although some fragmented reports are available in Africa [31,32]. A recent review by Tilahun et al, (2017) showed that antimicrobial resistance (AMR) data is not at all available for $>40 \%$ of the African countries. Plus, the level of resistance to commonly prescribed antibiotics, including azithromycin, is significantly higher [33]. Surveillance of the antimicrobial resistance, especially for the drugs of first choice: i.e. ceftriaxone and azithromycin, becomes very important in monitoring the emergence and spread of resistance $[14,32,34]$. With the above background, the aim of this review was to describe the current developments on azithromycin resistant gonococci. It is also imperative that changes in resistance patterns of gonococci be monitored continually to ensure optimal treatment both of the individual patients and for maintaining the efficacy of empiric therapy regimes. With the above background, the aim of this review was to describe the current developments on azithromycin resistant gonococci.

\section{Methods}

In this review we considered peer-reviewed journal articles, governmental documents and unpublished articles (thesis) reported in English language since 2010. Observational quantitative studies that reported the level of azithromycin resistant gonococci among individuals presumptive or confirmed for gonorrhea irrespective of 
gender and the age group were consulted. PubMed/ Medline, SCOPUS, Google scholar, Cochrane library and the Google database were source of the literatures. Combinations of the following key terms were considered to retrieve the articles; $<N$. gonorrhea/gonococcus, azithromycin resistant $N$. gonorrhea/gonococcus, antimicrobial resistance in gonococcus, epidemiology of azithromycin resistant gonococcus $>$. Studies reported before 2010 were excluded.

\section{Results}

\section{Action of azithromycin}

Azithromycin is a macrolide antibiotic and the sole member of the azalide subclass. It is derived from erythromycin; it has an aza-methyl substitution (insertion of a nitrogen atom) in the macrolide ring. This addition increases the stability with no change on the mechanism of action. The addition of the second amine group resulted in important advantages over erythromycin, including greater tissue penetration and an extended half-life. Azithromycin binds to the $50 \mathrm{~S}$ ribosome subunit preventing translocation of the peptidyl-tRNA, blocking the peptide exit channel in $50 \mathrm{~S}$ subunits by interacting with $23 \mathrm{~S}$ rRNA, and causing ribosomes to release incomplete polypeptides. This results in a bacteriostatic effect. Azithromy- cin demonstrate in vitro against a wide range of bacteria including gonococcus [22].

\section{Azithromycin resistance}

Resistance of $N$. gonorrhoeae to azithromycin slowly developed since 1990 in some areas of the world and then a number of similar reports came to the front globally $[14,16-21]$ and the reported prevalence varies across the nations (Table 1). Some countries like the US started Azithromycin susceptibility surveillance testing in 1992 and continue today as part of their AMR monitoring for early detection and action [8]. Likewise, the European Gonococcal Antimicrobial Surveillance Programme (EURO-GASP) was also established by in 2004 in response to the emerging antimicrobial resistance of $N$. gonorrhoeae [29]. In contrast, in most African countries there is no strong AMR surveillance not only for Azithromycin, but also for other antimicrobials to evaluate the temporal and spatial distribution and epidemiology of AMR in the continent [33].

Gonococci are known to use multiple mechanisms of antibiotic resistance. Genetically these changes may be mediated by either chromosomal or extra-chromosomal elements (plasmids) [7]. It is assumed that many of the resistance mechanisms evolve from specific mutations

Table 1 Magnitude of Azithromycin resistant gonococci measured by different methods

\begin{tabular}{|c|c|c|c|c|c|}
\hline Country & Author & Year of the study & Method of AST & $\begin{array}{l}\text { Magnitude of AZM } \\
\text { resistance (\%) }\end{array}$ & Reference \\
\hline Hungary & $\begin{array}{l}\text { Brunner et al. } \\
\text { Brunner et al. }\end{array}$ & 2014,2016 & $\begin{array}{l}\text { MIC strip test Liofilchem }{ }^{\circledast} \text {, } \\
\text { Agar dilution }\end{array}$ & $16-30.0$ & {$[14,26]$} \\
\hline India & Kulkarni et al. & 2018 & Disc diffusion with E-test & 5 & {$[24]$} \\
\hline China & $\begin{array}{l}\text { Jing-Yao et al.; Li, W et al. } \\
\text { Jiang et al. } \\
\text { Yin et al. }\end{array}$ & $\begin{array}{l}2016,2017 \\
2017 \\
2018\end{array}$ & Agar dilution method & $3.6-28.6$ & {$[35-38]$} \\
\hline Europe (EU) & Cole et al. & 2014 & Agar dilution & 5.3 & [39] \\
\hline United States & Kirkcaldy et al, & 2015 & Agar dilution methods & 0.4 & {$[40]$} \\
\hline Germany & $\begin{array}{l}\text { Regnath et al. } \\
\text { Beder et al. }\end{array}$ & $\begin{array}{l}2016 \\
2018\end{array}$ & E-test & $5.5-11.9$ & {$[18,29]$} \\
\hline Netherlands & Wind et al. & 2017 & Agar dilution & 1.2 & {$[25]$} \\
\hline Zimbabwe & Latif et al. & 2016 & E-test & 10 & {$[31]$} \\
\hline Uganda & Vandepitte et al. & 2014 & E-test & 16.2 & {$[32]$} \\
\hline Poland & Młynarczyk-Bonikowska et al. & 2014 & E-test & Sensitivity was at 38.5\% & {$[41]$} \\
\hline $\begin{array}{l}\text { South America and the } \\
\text { Caribbean }\end{array}$ & Dillon J-AR et al. & 2014 & Agar dilution & 10 & {$[42]$} \\
\hline France & Belkacem et al. & 2016 & E-test & 1 & [16] \\
\hline Cyprus & Cole et al. & 2015 & Agar dilution & 33.3 & {$[17]$} \\
\hline Greece & & 2015 & Agar dilution & 22.7 & \\
\hline Taiwan & Liu et al. & 2018 & Agar dilutiom & 14.6 & {$[20]$} \\
\hline Australia & Lahra et al. & 2016 & Agar dilution & 1.7 & {$[21]$} \\
\hline
\end{tabular}

Resistance to azithromycin was defined as an MIC $>0.5 \mathrm{mg} / \mathrm{L} \mathrm{[43]}$ 
from commensal Neisseria species that live in the oral cavity. Because $N$. gonorrhoeae is uniquely capable of assimilating external DNA during its life cycle, the transfer of chromosomally encoded resistance genes from commensal Neisseria species that have acquired resistance to various antimicrobials is rapid and extensive [8].

Many cases of macrolide resistance in clinical strains were linked to alteration of specific nucleotides in 23S rRNA within the large ribosomal subunit. Generally, bacterial resistance to macrolides may result from modification of the ribosomal target by either rRNA methylase-associated modification of the 23S rRNA or specific mutations in the 23S rRNA and/or from an over expressed efflux pump system. The rRNA methylases can cause macrolide resistance through blocking of macrolide binding to $23 \mathrm{~S}$ rRNA by methylating an adenosine residue at position 2058 (E. coli numbering system), which is located in peptidyl transferase domain V. Genes encoding rRNA methylase (referred to as macrolide-lincosamide-streptogramin B resistance genes, or erm genes) can be carried by conjugative transposons $[10,22,44-46]$. It is suggested that high level azithromycin resistant isolates were descendants of the low-level azithromycin resistant isolates and, accordingly, azithromycin exposure might provide the selection pressure for emergence of the high level azithromycin resistant phenotype [43, 47].

A recent study in UK by Chisholm and his research team have demonstrated that high-level azithromycin resistance in gonococci result from a single point mutation (A2059G) in the peptidyltransferase loop in domain $\mathrm{V}$ of the 23S rRNA gene. Mutation of a single allele is insufficient to confer high-level azithromycin resistance, but it can develop under selection pressure [48]. Similarly according to Wind et al. study (2017), exposure to azithromycin was significantly associated with A39T or G45D $m t r R$ mutations. This implies that, frequent azithromycin use in populations at high risk of contracting $N$. gonorrhoeae induces an increase in minimum inhibitory concentration (MIC), and may result in resistance [40, 49, 50]. A similar study in France also showed that mutations in domain $\mathrm{V}$ of $23 \mathrm{~S}$ rRNA, encoded by the $r \mathrm{rl}$ gene, were associated with Azithromycin resistance by gonococcus [16].

Shigemura and his research team in Japan likewise reported that a deletion mutation of the $m t r R$ promoter region is a possible mechanism of azithromycin resistance and may be a significant indicator for higher MICs $(0.5 \mu \mathrm{g} / \mathrm{ml}$ or higher) in N. gonorrhoeae infection [51]. A recently released data showed a decreased antimicrobial susceptibility of gonococci to azithromycin that may limit effectiveness of the drug $[52,53]$. The reduced azithromycin susceptibility has arisen through multiple mechanisms [54] as described above. Resistance to all major groups of antibiotics has arisen hand in hand with their extensive use in medicine and animal husbandry.

The two common antimicrobial susceptibility testing methods for gonococci are phenotypic and molecular techniques (based on the detection of specific antimicrobial resistance gene and mutations associated with resistance phenotypes). Disk diffusion and test for minimal inhibitory concentration (in the form of agar dilution, broth microdilution, agar gradient dilution (E-test)) methods are the two major phenotypic methods that commonly done in most laboratories around the world as these methods are relatively cheap and simple $[55,56]$ (Table 1).

\section{Future perspectives}

The only effective option for treating gonorrhea and stopping its spread has been the use of antimicrobial therapy. Currently, there is no vaccine to prevent gonococcal infection. Antimicrobial treatment options have diminished over time due to the progressive emergence of AMR to drugs previously used to treat gonorrhea. As a result, now we are left with limited options for treating gonorrhea. At this time, a number of studies are supporting the continued use of azithromycin in a combination therapy regimen for gonorrhea. However, the use of azithromycin in dual therapy for gonorrhoea has been increasingly questioned during the past few years, because of increasing azithromycin resistance in many countries [40, 43, 49]. Hence, we might not be able to rely on azithromycin to protect ceftriaxone [43]. Moreover, the emergence of extremely drug resistant (XDR) gonorrhoea argues for enhanced efforts to develop novel antimicrobial agents and a gonococcal vaccine [57]. It is also advised to exercise rational use of drugs and to promote continued antimicrobial stewardship for gonorrhea [58].

Studies are under way to look for new treatment modalities for the treatment of gonorrhea due to isolates possessing resistance to ceftriaxone and azithromycin; one of such studies is the use of fosfomycin alone and in combination with ceftriaxone or azithromycin [59]. In another study by Pettus and his colleagues, an in vitro assessment of azithromycin in combination with gentamicin demonstrated inhibition of growth and suggests that clinical trials may be warranted to assess the utility of this combination in treating gonorrhea infections [60]. Su et al. in China also tested the activity of a DNA Gyrase Inhibitor, ETX0914 against N. gonorrhoeae and suggested that it may be an effective treatment option for gonorrhea [52]. In a phase II trial of oral Solithromycin for the treatment of gonorrhea (2015), authors reported that single dose solithromycin, in doses of 1000 and $1200 \mathrm{mg}$ was $100 \%$ effective for treatment of culture-proven gonorrhea at genital, oral 
and rectal sites of infection and is a promising new agent for gonorrhea treatment [61].

The capacity and ease for genetic recombination and high transmissibility of resistant genes has made the development of new antibiotics a challenging area of research [39]. The choice of antibacterial agent must take into account the data generated by laboratory based surveillance of susceptibility. This surveillance would be useful not only in deciding the correct treatment but also in helping to detect the emergence of new antibiotic resistant traits and to monitor the effectiveness of prescribed treatment [7].

For better understand the molecular basis of $N$. gonorrhoeae infection, extensive genome sequencing studies have to be conducted on a diverse collection of strains from different geographical locations and collected over longer time periods [62]. This knowledge will facilitate disease prevention, surveillance and control, improve diagnostics and may help to facilitate the development of effective vaccines or new therapeutics.

\section{Conclusions}

Currently most countries around the globe are using dual therapy for the treatment of gonorrhea; ceftriaxone and azithromycine. The rationale for gonococcal combination therapy includes using different antimicrobials with different mechanisms of action to potentially mitigate the spread of antimicrobial resistance. There are a number of studies conducted on the AMR profile of gonococci and reported greater than 33\% level of azithromycin resistance globally. Gonococcus becomes resistant for this drug using different mechanisms. With no alternative antimicrobial treatment options for gonorrhoea and only a few new drugs in the development pipeline, AMR to extended spectrum cephalosporins and Azithromycin among $N$. gonorrhoeae is a major public health concern. So, ongoing surveillance and public health action are necessary to monitor trends in antimicrobial resistance, and rapidly assess clinical treatment failures. New antimicrobials are currently being assessed and further research should investigate alternative antimicrobial combinations, which will be essential to provide optimum therapy against this formidable pathogen.

Moreover, it has become substantive to initiate and sustained national and international efforts to reduce misuse of antibiotics so as to prevent further emergence and spread of antimicrobial resistance. It is necessary not only to monitor drug resistance and optimize treatment regimens, but also to gain deeper insight into how gonococcus develops drug resistance. Studies could also help in finding out new drug targets in $N$. gonorrhoeae and also a possibility of identification of new drugs for treating gonorrhoea.

\begin{abstract}
Abbreviations
AMR: Antimicrobial Resistance; ESC: Extended-spectrum Cephalosporin: MIC: Minimum inhibitory concentration; PID: Pelvic Inflammatory Disease; STD: Sexually Transmitted Disease; STI: Sexually Transmited Infection; tRNA: Transfer Ribonucleic acid; WHO: World Health Organization
\end{abstract}

\section{Acknowledgments}

We would like to thank Bahir Dar and Addis Ababa Universities and CDTAfrica for the provided opportunity to undertake this review.

\section{Authors' contributions}

AD and TA conceived the review topic and objectives. AD and DM participated in the study selection and write-up. TA and YW reviewed the manuscript critically for its scientific content. All authors reviewed and approved the manuscript.

\section{Funding}

We have received no fund for this particular review.

Availability of data and materials

All the generated data in this review are included in the manuscript.

Ethics approval and consent to participate

Not applicable in this section.

Consent for publication

Not applicable in this section.

\section{Competing interests}

Authors declare that they have no competing interests.

\section{Author details}

${ }^{1}$ Department of Medical Microbiology, College of Medicine and Health Sciences, Bahir Dar University, Bahir Dar, Ethiopia. ${ }^{2}$ Centre for Innovative Drug Development and Therapeutic Trials for Africa (CDT-Africa), Addis Ababa University, Bahir Dar, Ethiopia. ${ }^{3}$ Department of Health Biotechnology, Biotechnology Research Institute, Bahir Dar University, Bahir Dar, Ethiopia. ${ }^{4}$ Department of Medical Microbiology, Immunology and Parasitology, School of Medicine, College of Health Sciences, Addis Ababa University, Addis Ababa, Ethiopia.

Received: 24 June 2020 Accepted: 12 August 2020

Published online: 18 August 2020

\section{References}

1. World Health Organization. Global Health Sector Strategy On Sexually Transmitted Infections, 2016-2021; Towards Ending STIs. Geneva: WHO; 2016.

2. Okeke IN, Laxminarayan R, Bhutta ZA, Duse AG, Jenkins P, O'Brien TF, et al. Antimicrobial resistance in developing countries. Part I: recent trends and current status. Lancet Infect Dis. 5(8):481-93. https://doi.org/10.1016/s14733099(05)70189-4.

3. Namraj Goire MML, Chen M, Donovan B, Christopher K, Fairley RG, Kaldor J, Regan D, Ward J, Nissen MD, Sloots TP, Whiley DM. Molecular approaches to enhance surveillance of gonococcal antimicrobial resistance. Nat Rev Microbiol. 2014;12:223-9. https://doi.org/10.1038/nrmicro3217.

4. Amanda B. Gonorrhea. 2008. http://www.austincc.edu/microbio/2704w/ng. htm Accessed 22 Mar 2018.

5. WHO. Sexual and reproductive health: WHO; 2017. http://www.who.int/ reproductivehealth/topics/rtis/amr-gonorrhoea-on-the-rise/en/ Accessed 22 Mar 2018.

6. Bodoev IN, Il'ina EN. Molecular mechanisms of drug resistance Neisseria Gonorrhoeae history and prospects. Mol Gen Mikrobiol Virusol. 2015; 33(3):22-7

7. Achchhe Lal Patel UC, Sachdev D, Sachdeva PN, Bala M, Saluja D. An insight into the drug resistance profile \& mechanism of drug resistance in Neisseria gonorrhoeae. Indian J Med Res. 2011;134(4):419-31.

8. Lancaster JW, Mahoney MV, Mandal S, Lawrence KR. Update on treatment options for Gonococcal infections. Pharmacotherapy. 2015;35(9):856-68.

9. Ezewudo MN, Joseph SJ, Castillo-Ramirez S, Dean D, del Rio C, Didelot X, et al. Population structure of Neisseria gonorrhoeae based on whole 
genome data and its relationship with antibiotic resistance. PeerJ. 2015;3: e806. https://doi.org/10.7717/peerj.806.

10. Unemo M, Shafer WM. Antimicrobial resistance in Neisseria gonorrhoeae in the 21st century: past, evolution, and future. Clin Microbiol Rev. 2014;27(3):587-613.

11. McConnell J. ASM Microbe 2017; 2017. p. 1.

12. WHO. Sexual and reproductive health 2015. http://www.who.int/ reproductivehealth/news/stis-estimates-2015/en/ Accessed 22 Mar 2018.

13. Wi T, Lahra MM, Ndowa F, Bala M, Dillon JR, Ramon-Pardo P, et al. Antimicrobial resistance in Neisseria gonorrhoeae: Global surveillance and a call for international collaborative action. PLoS Med. 2017;14(7):e1002344. https://pubmed.ncbi.nlm.nih.gov/28686231/.

14. Brunner A, Nikodem E, Jeney C, Szabo D, Marschalko M, Karpati S, et al. Emerging azithromycin-resistance among the Neisseria gonorrhoeae strains isolated in Hungary. Ann Clin Microbiol Antimicrob. 2016;15(53):6. https:// doi.org/10.1186/s12941-016-0166-9.

15. APRd C-L, Barros dos Santos KT, Moreira BM, SEL F, Bonelli RR. Antimicrobial resistance in Neisseria gonorrhoeae: history, molecular mechanisms and epidemiological aspects of an emerging global threat. Braz J Microbiol. 2017;48(4):617-28. https://doi.org/10.1016/j.bjm.2017.06.001.

16. Belkacem A, Jacquier H, Goubard A, Mougari F, La Ruche G, Patey O, et al. Molecular epidemiology and mechanisms of resistance of azithromycin-resistant Neisseria gonorrhoeae isolated in France during 2013-14. J Antimicrob Chemother. 2016;71(9):2471-8. https://doi.org/10. 1093/jac/dkw182.

17. Cole MJ, Spiteri G, Jacobsson S, Pitt R, Grigorjev V, Unemo M. Is the tide turning again for cephalosporin resistance in Neisseria gonorrhoeae in Europe? Results from the 2013 European surveillance. BMC Infect Dis. 2015; 15(321):015-1013.

18. Buder S, Dudareva S, Jansen K, Loenenbach A, Nikisins S, Sailer A, et al. Antimicrobial resistance of Neisseria gonorrhoeae in Germany: low levels of cephalosporin resistance, but high azithromycin resistance. BMC Infect Dis. 2018;18(1):018-2944

19. Bercot B, Belkacem A, Goubard A, Mougari F, Sednaoui P, La Ruche G, et al. High-level azithromycin-resistant Neisseria gonorrhoeae clinical isolate in France, march 2014. Euro Surveill. 2014;19:44.

20. Liu YH, Huang YT, Liao CH, Hsueh PR. Antimicrobial susceptibilities and molecular typing of neisseria gonorrhoeae isolates at a medical Centre in Taiwan, 2001-2013 with an emphasis on high rate of azithromycin resistance among the isolates. Int J Antimicrob Agents. 2018;22(18):30035-9.

21. Lahra MM, Enriquez RP. Australian Gonococcal surveillance Programme, 1 July to 30 September 2015. Commun Dis Intell Q Rep. 2016;40(1):E179-81.

22. KIM M, WELCH, Tanis. Update on azithromycin and cardiac side effects. The Southwest Respiratory and Critical Care Chronicles, [S.I.], v. 2, n. 5, p. 48-51, dec. 2013.ISSN 2325-9205. 2018. http://pulmonarychronicles.com/index. php/pulmonarychronicles/article/view/107/224. Accessed 7 April 2018.

23. Unemo M, Del Rio C, Shafer WM. Antimicrobial resistance expressed by Neisseria gonorrhoeae: a major global public health problem in the $21 \mathrm{st}$ century. Microbiol Spectr. 2016:4(3):0009-2015

24. Kulkarni SV, Bala M, Muqeeth SA, Sasikala G, Nirmalkar AP, Thorat R, et al. Antibiotic susceptibility pattern of Neisseria gonorrhoeae strains isolated from five cities in India during 2013-2016. J Med Microbiol. 2018;67(1):22-8.

25. Wind CM, van der Loeff MF S, van Dam AP, de Vries HJ, van der Helm Jل J.22Trends in antimicrobial susceptibility for azithromycin and ceftriaxone in Neisseria gonorrhoeae isolates in Amsterdam, the Netherlands, between 2012 and 2015. Euro Surveill. 2017;22(1):1560-7917.

26. Brunner A, Nemes-Nikodem E, Mihalik N, Marschalko M, Karpati S, Ostorhazi E. Incidence and antimicrobial susceptibility of Neisseria gonorrhoeae isolates from patients attending the national Neisseria gonorrhoeae reference laboratory of Hungary. BMC Infect Dis. 2014;14(433):1471-2334.

27. Papp JR, Abrams AJ, Nash E, Katz AR, Kirkcaldy RD, O'Connor NP, et al. Azithromycin resistance and decreased ceftriaxone susceptibility in Neisseria gonorrhoeae, Hawaii. USA Emerg Infect Dis. 2017;23(5):830-2.

28. Nemes-Nikodem E, Brunner A, Toth B, Toth V, Banvolgyi A, Ostorhazi E. Antimicrobal resistance of Neisseria gonorrhoeae strains in Hungary. Orv Hetil. 2015;156(6):226-9.

29. Regnath T, Mertes T, Ignatius R. Antimicrobial resistance of Neisseria gonorrhoeae isolates in south-West Germany, 2004 to 2015: increasing minimal inhibitory concentrations of tetracycline but no resistance to thirdgeneration cephalosporins. Euro Surveill. 2016;21(36):1560-7917.
30. Mehta SD, Maclean I, Ndinya-Achola JO, Moses S, Martin I, Ronald A, et al. Emergence of quinolone resistance and cephalosporin MIC creep in Neisseria gonorrhoeae isolates from a cohort of young men in Kisumu, Kenya, 2002 to 2009. Antimicrob Agents Chemother. 2011;55(8):3882-8.

31. Latif AS, Gwanzura L, Machiha A, Ndowa F, Tarupiwa A, Gudza-Mugabe M, et al. Antimicrobial susceptibility in Neisseria gonorrhoeae isolates from five sentinel surveillance sites in Zimbabwe, 2015-2016. Sex Transm Infect. 2018; 94(1):62-6.

32. Vandepitte J, Hughes P, Matovu G, Bukenya J, Grosskurth H, Lewis DA. High prevalence of ciprofloxacin-resistant gonorrhea among female sex workers in Kampala, Uganda (2008-2009). Sex Transm Dis. 2014;41(4):233-7.

33. Tadesse BT, Ashley EA, Ongarello S, Havumaki J, Wijegoonewardena M, Gonzalez IJ, et al. Antimicrobial resistance in Africa: a systematic review. BMC Infect Dis. 2017;17(1):017-2713.

34. Leopold SJ, van Leth F, Tarekegn H, Schultsz C. Antimicrobial drug resistance among clinically relevant bacterial isolates in sub-Saharan Africa: a systematic review. J Antimicrob Chemother. 2014;69(9):2337-53.

35. Liang JY, Cao WL, Li XD, Bi C, Yang RD, Liang YH, et al. Azithromycinresistant Neisseria gonorrhoeae isolates in Guangzhou, China (2009-2013): coevolution with decreased susceptibilities to ceftriaxone and genetic characteristics. BMC Infect Dis. 2016;16(152):016-1469.

36. Li W, Zhu BY, Qin SQ, Yang MC, Liang M, He S, et al. Surveillance of antimicrobial susceptibilities of Neisseria gonorrhoeae from 2013 to 2015 in Guangxi Province, China. Jpn J Infect Dis. 2017;26(10):169.

37. Jiang F-X, Lan Q, Le W-J, Su X-H. Antimicrobial susceptibility of Neisseria gonorrhoeae isolates from Hefei (2014-2015): genetic characteristics of antimicrobial resistance. BMC Infect Dis. 2017;17:366. https://doi.org/10. 1186/s12879-017-2472-z.

38. Yin YP, Han Y, Dai XQ, Zheng HP, Chen SC, Zhu BY, et al. Susceptibility of Neisseria gonorrhoeae to azithromycin and ceftriaxone in China: A retrospective study of national surveillance data from 2013 to 2016. PLoS Med. 2018;15(2):e1002499. https://www.ncbi.nlm.nih.gov/pmc/articles/PMC5 800545/.

39. Cole MJ, Spiteri G, Chisholm SA, Hoffmann S, Ison CA, Unemo M, et al. Emerging cephalosporin and multidrug-resistant gonorrhoea in Europe. Euro Surveill. 2014;19(45):20955.

40. Kirkcaldy RD, Soge O, Papp JR, Hook EW 3rd, del Rio C, Kubin G, et al. Analysis of Neisseria gonorrhoeae azithromycin susceptibility in the United States by the Gonococcal isolate surveillance project, 2005 to 2013. Antimicrob Agents Chemother. 2015;59(2):998-1003.

41. Mlynarczyk-Bonikowska B, Kujawa M, Mlynarczyk G, Malejczyk M, Majewski S. Resistance to azithromycin of Neisseria gonorrhoeae strains isolated in Poland in 2012-2013 years. Med Dosw Mikrobiol. 2014;66(3-4):209-14.

42. Dillon J-AR, Trecker MA, Thakur SD. Two decades of the gonococcal antimicrobial surveillance program in South America and the Caribbean: challenges and opportunities. Sex Transm Infect. 2014;89:36-41.

43. Unemo M, Workowski K. Dual antimicrobial therapy for gonorrhoea: what is the role of azithromycin? Lancet Infect Dis. 2018;6(18):30162.

44. Fauci B, Kasper H, Longo J, et al. Harrison's PRINCIPLES OF INTERNAL MEDIC NE. Gonococcal infections. US: The McGraw-Hill Companies; 2008.

45. Warren L. Review of medical Microbiology and immunology. 1oth ed. gram negative Cocci. United States of America: The McGraw-Hill Companies; 2008

46. Wu A, Buono S, Katz KA, Pandori MW. Clinical Neisseria gonorrhoeae isolates in the United States with resistance to azithromycin possess mutations in all 23S rRNA alleles and the mtrR coding region. Microb Drug- Resist. 2011; 17(3):425-7.

47. Chisholm SA, Ison C. Emergence of high-level azithromycin resistance in Neisseria gonorrhoeae in England and Wales. Euro Surveill. 2008;13:15.

48. Chisholm SA, Dave J, Ison CA. High-level azithromycin resistance occurs in Neisseria gonorrhoeae as a result of a single point mutation in the 235 rRNA genes. Antimicrob Agents Chemother. 2010;54(9):3812-6.

49. Wind CM, de Vries E, van der Loeff MF S, van Rooijen MS, van Dam AP, WHB D, et al. Decreased azithromycin susceptibility of Neisseria gonorrhoeae isolates in patients recently treated with azithromycin. Clin Infect Dis. 2017:65(1):37-45.

50. Shigemura K, Osawa K, Miura M, Tanaka K, Arakawa S, Shirakawa T, et al. Azithromycin resistance and its mechanism in Neisseria gonorrhoeae strains in Hyogo, Japan. Antimicrob Agents Chemother. 2015:59(5):2695-9. 
51. Shigemura K, Osawa K, Miura M, Tanaka K, Arakawa S, Shirakawa T, et al. Azithromycin Resistance and Its Mechanism in Neisseria gonorrhoeae Strains in Hyogo, Japan. Antimicrobial Agents Chemother. 2015;59(5):26959. https://doi.org/10.1128/aac.04320-14.

52. Su XH, Wang BX, Le WJ, Liu YR, Wan C, Li S, et al. Multidrug-resistant Neisseria gonorrhoeae isolates from Nanjing, China, are sensitive to killing by a novel DNA Gyrase inhibitor, ETX0914 (AZD0914). Antimicrob Agents Chemother. 2015;60(1):621-3.

53. Martin I, Sawatzky P, Liu G, Allen V, Lefebvre B, Hoang L, et al. Decline in decreased cephalosporin susceptibility and increase in azithromycin resistance in Neisseria gonorrhoeae, Canada. Emerg Infect Dis. 2016;22(1):65-7.

54. Grad YH, Harris SR, Kirkcaldy RD, Green AG, Marks DS, Bentley SD, et al. Genomic epidemiology of Gonococcal resistance to extended-Spectrum Cephalosporins, macrolides, and Fluoroquinolones in the United States, 2000-2013. J Infect Dis. 2016;214(10):1579-87.

55. Clinical and Laboratory Standards Institute (CLSI). Performance Standards for Antimicrobial Susceptibility Testing; 29th Ed. CLSI document M100. 2019.

56. Khan Z, Siddiqui M, Park S. Current and Emerging Methods of Antibiotic Susceptibility Testing. Diagnostics. 2019;9(49). https://doi.org/10.3390/ diagnostics9020049.

57. Lewis DA. Global resistance of Neisseria gonorrhoeae: when theory becomes reality. Curr Opin Infect Dis. 2014;27(1):62-7.

58. Clifton S, Bolt H, Mohammed H, Town K, Furegato M, Cole M, et al. Prevalence of and factors associated with MDR Neisseria gonorrhoeae in England and Wales between 2004 and 2015: analysis of annual crosssectional surveillance surveys. J Antimicrob Chemother. 2018;73(4):923-32.

59. Hauser $C$, Hirzberger $L$, Unemo $M$, Furrer $H$, Endimiani A. In vitro activity of fosfomycin alone and in combination with ceftriaxone or azithromycin against clinical Neisseria gonorrhoeae isolates. Antimicrob Agents Chemother. 2015;59(3):1605-11.

60. Pettus K, Sharpe S, Papp JR. In vitro assessment of dual drug combinations to inhibit growth of Neisseria gonorrhoeae. Antimicrob Agents Chemother. 2015;59(4):2443-5.

61. Hook IIIEW, Golden M, Jamieson BD, Dixon PB, Harbison HS, Lowens S, et al. A phase 2 trial of Oral Solithromycin $1200 \mathrm{mg}$ or $1000 \mathrm{mg}$ as single-dose Oral therapy for uncomplicated Gonorrhea. Clin Infect Dis. 2015;61(7):1043-8. https://doi.org/10.1093/cid/civ478.

62. Quillin SJ, Seifert HS. Neisseria gonorrhoeae host adaptation and pathogenesis. Nat Rev Microbiol. 2018;16(4):226-40.

\section{Publisher's Note}

Springer Nature remains neutral with regard to jurisdictional claims in published maps and institutional affiliations.

Ready to submit your research? Choose BMC and benefit from:

- fast, convenient online submission

- thorough peer review by experienced researchers in your field

- rapid publication on acceptance

- support for research data, including large and complex data types

- gold Open Access which fosters wider collaboration and increased citations

- maximum visibility for your research: over $100 \mathrm{M}$ website views per year

At BMC, research is always in progress.

Learn more biomedcentral.com/submissions 